\title{
ANALISIS KELAYAKAN USAHA PEMBIBITAN CENGKEH (STUDI KASUS DESA KEDUNGLURAH KECAMATAN POGALAN KABUPATEN TRENGGALEK)
}

\author{
Idah Lumhatul Fuad \\ ilumfuad@yudharta.ac.id
}

\begin{abstract}
ABSTRAK
Tujuan penelitian ini adalah mengetahui dampak usaha terhadap peningkatan ekonomi rumah tangga dan menganalisis finansial usaha pembibitan cengkeh petani. Penelitian ini dilakukan di Desa Kedunglurah Kecamatan Pogalan Kabupaten Trenggalek pada bulan Oktober 2014. Pengumpulan data dengan menggunakan teknik observasi dan sensus. Analisis partisipasi diukur menggunakan skala likert, untuk menganalisis hubungan identitas diri dengan partisipasi menggunakan korelasi Rank Spearman dan analisis kelayakan finansial usaha menggunakan B/C Ratio. Hasil analisis deskriptif menunjukkan bahwa tingkat partisipasi responden 66,67\% memiliki partisipasi tinggi, 23,81\% memiliki partisipasi sedang dan partisipasi rendah adalah 9,52\%. Tingkat partisipasi ini dipengaruhi oleh faktor pendidikan. Dari aspek ekonomi aktivitas pembibitan belum berkontribusi nyata bagi peningkatan pendapatan rumah tangga anggota. Hasil analisis finansial usaha menggunakan analisis B/C Ratio diperoleh nilai 1,86 > 1,00. Sehingga secara finansial, usaha pembibitan ini dikatakan layak.
\end{abstract}

Kata kunci:Pembibitan Cengkeh, Kelayakan Usaha, B/C ratio.

\section{PENDAHULUAN}

Cengkeh adalah salah satu komoditas kehutanan unggulan. Permintaan pasar domestik dan pasar ekspor yang terus meningkat, sedangkan stok bibit dalam negeri belum memenuhi permintaan pasar, sehingga memberikan peluang bisnis bagi para petani maupun pengusaha untuk membudidayakan tanaman cengkeh.

Masyarakat Desa Kedunglurah adalah satu diantara yang mengembangkan usaha pembibitan cengkeh sebagai kegiatan yang dilakukan dalam waktu yang lama, namun hasil yang dicapai masih kurang memuaskan terutama tidak terbangunnya kemandirian masyarakat secara berkelanjutan.

Keberlanjutan partisipasi masyarakat dalam suatu program pemberdayaan ditentukan oleh besarnya manfaat yang diterima diantaranya manfaat ekonomi khususnya pendapatan rumah tangga, manfaat sosial yaitu memberikan peningkatan pengetahuan, persepsi dan alih teknologi serta manfaat ekologi. Selain itu, kegiatan yang dilaksanakan harus memperhatikan kelayakan usaha dari aspek finansial. Penelitian ini bertujuan untuk menganalisis faktor yang mempengaruhi tingkat partisipasi anggota dalam pengembangan usaha pembibitan cengkeh oleh petani, menganalisis dampak usaha terhadap peningkatan ekonomi 
rumah tangga anggota petani, dan menganalsisi finansial usaha pembibitan cengkeh yang dikembangkan oleh petani.

Penelitian ini diharapkan dapat menjadi informasi dan bahan masukan dalam perencanaan dan pengembangan usaha pembibitan cengkeh model pemberdayaan masyarakat melalui kelompok tani.

Dalam penelitian ini diduga tingkat partisipasi dipengaruhi oleh faktor identitas diri anggota kelompok tani, pengembangan usaha pembibitan cengkeh oleh petani memberikan kontribusi bagi pendapatan rumah tangga dan usaha pembibitan cengkeh melalui kelompok tani layak secara finansial.

\section{METODE PENELITIAN}

Penelitian ini dilaksanakan di Desa Kedunglurah Kecamatan Pogalan Kabupaten Trenggalek pada bulan Oktober 2014.

Ada dua jenis data yang dikumpulkan yaitu data primer dan data sekunder. Data primer meliputi identitas diri responden, partisipasi anggota kelompok dalam tahap perencanaan, pelaksanaan, monitoring dan evaluasi, data input dan data output usaha cengkeh. Data-data primer ini bersumber dari anggota dan pembina petani. Sedangkan data sekunder yang diperlukan adalah keadaan umum lokasi penelitian yaitu data kependudukan dan sosial ekonomi penduduk.
Data sekunder ini diperoleh dari data statistik Desa Kedunglurah.

Ada dua teknik yang telah digunakan dalam mengumpulkan data yaitu teknik observasi dan sensus. Teknik observasi merupakan suatu observasi awal untuk mengetahui keadaan umum lokasi penelitian. Sedangkan teknik sensus yaitu semua petani merupakan sampel, sehingga semua anggota diwawancarai. Wawancara dilakukan melalui door to door dengan menggunakan pertanyaan-pertanyaan yang telah disusun (kuisioner).

\section{Analisis Data}

Analisis data menggunakan analisis kuantitatif dan kualitatif. Total biaya (cost) adalah semua biaya produksi yang dikeluarkan baik bahan dan alat maupun tenaga kerja dan disesuaikan dengan nilai sekarang (present value). Penerimaan (revenue) adalah penerimaan produsen dari hasil penjualan outputnya. Penerimaan dihitung dengan menggunakan persamaan 2 (Alam $d k k, 2009$ ):

$$
\mathrm{TR}=\mathrm{P} \times \mathrm{Q}
$$

$$
\begin{aligned}
& \text { Ket: } \mathrm{TR}=\text { Total Revenue } \\
& \mathrm{P}=\text { harga produk per unit } \\
& \mathrm{Q}=\text { jumlah produk yang dijual } \\
& \text { Keuntungan (benefit) adalah } \\
& \text { penerimaan dikurangi total biaya } \\
& (\cos t) \text {. }
\end{aligned}
$$




\section{HASIL DAN PEMBAHASAN}

\section{Pengaruh Partisipasi Terhadap Keberlanjutan Usaha \\ Partisipasi}

Hasil uji validitas instrumen menggunakan Korelasi Pearson menunjukkan bahwa instrumen yang digunakan adalah valid atau sahih. Artinya bahwa instrumen yang digunakan mampu mengukur apa yang ingin diukur oleh peneliti. Sedangkan uji reliabilitas instrumen menggunakan Cronbach Alpha diperoleh nilai 0,75 . Berdasarkan nilai tersebut sebagaimana disajikan pada persamaan 3 berikut ini (Alam, $d k k$ 2009):

$$
\text { Profit }=\mathrm{TR}-\mathrm{TC}
$$

Ket: $\mathrm{TR}=$ Total revenue,

$\mathrm{TC}=$ Total cost

Analisis finansial usaha menggunakan

Benefit Cost Ratio (B/C Ratio).

B/C Ratio dihitung dengan menggunakan persamaan 4 (Alam $d k k, 2009$ ):

$\mathrm{B} / \mathrm{C}$.

Ket.: $\mathrm{B}=$ Benefit,

$$
\mathrm{C}=\text { Cost }
$$

Dalam penelitian ini analisis sensitivitas dilakukan untuk melihat pengaruh perubahan harga jual satuan output terhadap nilai B/C Ratio. Tujuannya adalah untuk menentukan harga jual berdasarkan asumsi analisis yang ditetapkan. diperoleh Cronbach Alpha > 0,60, maka instrumen yang digunakan dapat diandalkan atau dipercaya.

\section{Dampak Ekonomi Rumah Tangga}

Berdasarkan hasil penelitian bahwa selama mengusahakan tanaman cengkeh, anggota kelompok baru sekali menerima pembagian upah kerja. Bibit yang telah diusahakan selain untuk dijual, juga ditanam dikebun mereka masing-masing sehingga usaha ini berdampak secara tidak langsung.

\section{Analisis Finansial}

Total bibit yang diproduksi oleh petani sebanyak 7.000 bibit. Analisis finansial usaha pembibitan ini dihitung dengan menggunakan asumsi-asumsi sebagai berikut: (1) Harga jual yang digunakan adalah harga paling rendah (3) yaitu Rp 3.000,- per bibit; (2) Pembibitan berlaku pada 1 kali musim tanam yaitu selama 6 bulan. Pembibitan ini terhitung dari perkecambahan benih hingga bibit siap panen; (3) Semua faktor produksi yang dikeluarkan atau digunakan sebagaimana disajikan dalam tabel 6 dihitung dalam biaya produksi berdasarkan patokan harga barang bulan Oktober 2014. 
Tabel 5. Analisis Usahatani pembibitan

\begin{tabular}{|c|c|c|c|c|c|}
\hline I. IN] & & & & & \\
\hline $1.1 \mathrm{~B}$ & an dan Alat & & & & \\
\hline No & Alat dan bahan & Satuan & $\begin{array}{l}\text { Jumlah } \\
\text { Satuan }\end{array}$ & Harga satuan & Nilai (Rp) \\
\hline 1 & Plastik bening & Meter & 50 & Rp 2.990,- & Rp 149.500,- \\
\hline 2 & $\begin{array}{l}\text { Paranet } 40 \% \text { lebar } 3 \\
\text { meter }\end{array}$ & Meter & 100 & Rp 3.000,- & Rp 300.000,- \\
\hline 3 & Sprayer & Buah & 2 & Rp 50.000,- & Rp 100.000,- \\
\hline 4 & Saringan alumanium & Buah & 10 & Rp 10.000,- & Rp 100.000,- \\
\hline 5 & Saringan santan & Buah & 10 & Rp 5.000,- & Rp 50.000,- \\
\hline 6 & Saringan tepung & Buah & 10 & Rp 15.000,- & Rp 150.000,- \\
\hline 7 & Wadah/loyang & Buah & 20 & Rp 5.000,- & Rp 100.000,- \\
\hline 8 & Cangkul & Buah & 3 & Rp 40.000,- & Rp 120.000,- \\
\hline 9 & Parang & Buah & 20 & Rp 45.000,- & Rp 900.000,- \\
\hline 10 & Sekop & Buah & 3 & Rp 55.000,- & Rp 165.000,- \\
\hline 11 & Tempat sangrai/kukus & Buah & 1 & Rp 50.000,- & Rp 50.000,- \\
\hline 12 & Polybag $12 \times 15^{*}$ & $\mathrm{Kg}$ & 3 & Rp 19.500,- & Rp 58.500,- \\
\hline 13 & Polybag 15 × $20^{*}$ & $\mathrm{Kg}$ & 1 & Rp 19.500,- & Rp 19.500,- \\
\hline 14 & Sewa mobil & Hari & 1 & Rp 250.000,- & Rp 250.000,- \\
\hline 15 & Sewa lahan & Meter & 2.000 & Rp 25,- & Rp 50.000,- \\
\hline 16 & Insektisida Antrapol* & $\mathrm{Kg}$ & 1 & Rp 125.000,- & Rp 125.000,- \\
\hline 17 & NPK (Phonska)* & $\mathrm{Kg}$ & 30 & Rp 2.300,- & Rp 69.000,- \\
\hline 18 & Pembungkus nasi* & Lembar & 20 & Rp 2.000,- & Rp 40.000,- \\
\hline 19 & Benih & $\mathrm{Kg}$ & 0,5 & Rp 5.000.000,- & Rp 2.500.000,- \\
\hline 20 & Pupuk organik & Karung & 20 & Rp 10.000,- & Rp 200.000,- \\
\hline 21 & Furadan & $\mathrm{Kg}$ & 5 & Rp 17.500,- & $\operatorname{Rp} 87.500,-$ \\
\hline 22 & Racun sidafos & Liter & 5 & Rp 50.000,- & Rp 250.000,-- \\
\hline Sub t & & & & & Rp 5.834.000,- \\
\hline $1.2 \mathrm{~T}$ & aga Kerja & & & & \\
\hline No & Kegiatan & Satuan & $\begin{array}{l}\text { Jumlah } \\
\text { Satuan }\end{array}$ & Harga & Nilai (Rp) \\
\hline 23 & - Penyiapan lahan & HOK & 5 & Rp 50.000,- & Rp 250.000,- \\
\hline 24 & - Penyapihan & HOK & 7 & Rp 50.000,- & Rp 350.000,- \\
\hline 25 & - Pemupukan & $\mathrm{HOK}$ & 15 & Rp 50.000,- & Rp 750.000,- \\
\hline 26 & - Pemanenan & $\mathrm{HOK}$ & 3 & Rp 50.000,- & Rp 150.000,- \\
\hline Sub t & & & & & Rp 1.500.000,- \\
\hline Total & & & & & Rp 7.334.000,- \\
\hline II. O & PUT & & & & \\
\hline Pene & aan & & & & Rp 21.000.000,- \\
\hline Keun & ggan & & & & Rp 13.666.000,- \\
\hline Bene & Cost Ratio & & & & 1,86 \\
\hline
\end{tabular}

Sumber: Hasil analisis data primer (2014) 
dengan B/C Rationya adalah 1,86. Artinya bahwa setiap Rp 1,- biaya yang dikeluarkan, akan menghasilkan tambahan manfaat sebesar Rp 1,86,-. Oleh karena B/C Ratio-nya lebih dari 1 maka secara finansial, usaha pembibitan cengkeh yang dilakukan petani dikatakan layak.

\section{Analisis Sensitivitas}

Analisis sensitivitas pada penelitian ini dilakukan dengan menurunkan harga jual bibit hingga memperoleh nilai B/C Ratio 1,00.

Hasil analisis sensitivitas menunjukkan bahwa pada harga jual per bibit Rp 3.000,maka nilai B/C Ratio-nya adalah 1,86 dan pada B/C Ratio 1,00 memiliki harga jual per bibit Rp 2.096,-. Berdasarkan asumsi-asumsi biaya yang digunakan, maka total biaya yang dikeluarkan untuk menghasilkan satu bibit adalah Rp 1.048,-, Sehingga harga jual minimal setiap bibit adalah Rp 2.096,-.

\section{KESIMPULAN DAN SARAN}

\section{Kesimpulan}

Berdasarkan hasil penelitian dapat disimpulkan bahwa tingkat partisipasi anggota kelompok tani pada kegiatan perencanaan, pelaksanaan, serta monitoring dan evaluasi dalam usahatani adalah $66,67 \%$ sebagai partisipasi tinggi, partisipasi sedang yaitu $23,81 \%$ dan partisipasi rendah yaitu $9,52 \%$. Tingkat partisipasi tersebut dipengaruhi oleh faktor pendidikan.

Kontribusi usaha pada peningkatan ekonomi rumah tangga belum dirasakan secara nyata karena sistem pengelolaan keuangan yang menjadikan pendapatan usaha sebagai modal kelompok. Namun secara tidak langsung dari aspek ekonomi menguntungkan karena selain untuk dijual juga ditanam di kebun mereka masing-masing dan dapat dipanen setelah 5-10 tahun pasca tanam 2012. Usaha pembibitan cengkeh yang dilakukan kelompok layak secara finansial dengan nilai B/C Ratio sebesar 1,86.

\section{Saran}

Implikasi dari hasil penelitian di atas disarankan agar upaya sosialisasi tujuan program diperkuat lagi, sehingga terbangun pemahaman yang lebih kuat supaya partisipasi anggota kelompok lebih meningkat. Anggaran Dasar dan Anggaran Rumah Tangga lebih diperkuat agar mengikat kepentingan anggota kelompok. 


\section{DAFTAR PUSTAKA}

Adiwilaga, 1982. Ilmu Usahatani. Penerbit Alumni Bandung. Bandung

Anonymous. 2012. Studi Kelayakan Usaha. http://ecolife001crp.blog spot.com/2009/01/studikelayakan-usaha.html. Diakses tanggal 29 Juni 2014.

Hanafi, Abdul A. 2011. Agroindustri Minuman Sari Buah Apel di kecamatan Poncokusumo Kabupaten Malang. Skripsi Fakultas Pertanian Universitas Brawijaya. Malang.

Harahap, Sofyan S. 2001. Akuntansi Aktiva Tetap Sekolah Tinggi Ilmu Ekonomi YKPN. Yogyakarta.

Hernanto, F. 1993. Ilmu Usahatani. Penebar Swadaya. Jakarta.

Kasmir. 2003. Studi Kelayakan Bisnis. Rineka. Jakarta.

Mulyadi, 2000, Akuntansi Biaya, Edisi ke5, Penerbit Aditya Media, Yogyakarta.

Ratag, J, 1982. Dasar - Dasar Pengelolaan Usahatani. Fakultas Pertanian Universitas Sam Ratulangi. Manado.

Soekartawi, 1995. Analisis Usahatani. Universitas Indonesia. Jakarta.

Soekartawi. 1987. Ilmu Usahatani dan Penelitian untuk Pengembangan Pertanian Kecil. UI-Press. Jakarta.
Soekarwati. 2006. Analisis Usaha Tani. Jakarta: UI Press

Umar, Husein. 1997. Studi Kelayakan Bisnis, Edisi 2. Gramedia. Yogyakarta 